\title{
Correlation between Microstructure/Fracture Surfaces and Material Properties
}

\author{
R. BidulskÝ ${ }^{a, *}$, J. BidulskÁ ${ }^{b}$ And M. ACtis GRANDE ${ }^{a}$ \\ ${ }^{a}$ Department of Applied Science and Technology, Politecnico di Torino, T. Michel 5, 15 100, Alessandria, Italy \\ ${ }^{b}$ Department of Metals Forming, Faculty of Metallurgy, Technical University of Košice \\ Letná 9, 04200 Košice, Slovakia
}

\begin{abstract}
The present paper deals with the evaluation of the effect of different vacuum heat treatments on the microstructure and fracture surfaces of a low alloyed sintered $\mathrm{Fe}-[1.5 \mathrm{Cr}-0.2 \mathrm{Mo}]-0.6 \mathrm{C}$ steel, in correlation with the mechanical and plastic properties achieved. The heat treatment consists of the sintering process in vacuum furnace at $1393 \mathrm{~K}$ for $1800 \mathrm{~s}$, followed by different cooling conditions and an integrated final tempering at $473 \mathrm{~K}$ for $3600 \mathrm{~s}$. The average cooling rates, calculated in the range of $1393 \mathrm{~K}$ to $673 \mathrm{~K}$, were $0.1,0.235,3$, and $6 \mathrm{~K} / \mathrm{s}$, respectively. Vacuum heat treatment is supporting the bainitic-martensitic microstructure, the higher the faster cooling rate applied. This provides a marked increase in strength coupled to a decrease in ductility. The decrease of the impact energy after heat treatment is justified by the microstructural changes, especially if a part of bainite is converted to brittle martensite. Samples with bainitic microstructure presented higher impact energies than those with martensitic microstructure. This is fully confirmed by the fracture surface analysis at higher magnification, revealing three main micromechanisms of fracture: brittle, ductile and quasi-cleavage.
\end{abstract}

PACS: 81.05.Bx, 81.20.Ev, 81.40.-z, 62.20.mm, 62.25.Mn

\section{Introduction}

Powder metallurgy (PM) is a well established technology for manufacturing parts to net or near net shape.

Some recent developments have been introduced, with the goal of improving the PM parts performance. In terms of chemical compositions, systems using cheaper alloying elements such as $\mathrm{Cr}$ and $\mathrm{Mn}$ [1-3] were introduced into the market in the last years. As for the density improvements or porosity control, compacting techniques have been developed, including various methods of severe plastic deformation [4-7]. Sintering has also been modified, in order to get the full control of the processing conditions, by means of a deep analysis of the temperature profile, sintering atmosphere purity, oxygen/carbon ratio, dew points, cooling rates [8-13].

Different heat treatments can also be used. The vacuum heat treatment is a very successful secondary operation tool, due to its high flexibility.

The final microstructural constituents mainly depend on the cooling rate, dimension of the part and, clearly, on chemical composition. In any case, heat treatments are necessary to tune the mechanical properties to the final requirements and consequently, the effect of the heat treatments on the microstructure and mechanical properties has proven to be a very dynamic research field during the last years [14, 15].

\footnotetext{
* corresponding author; e-mail: robert.bidulsky@polito.it
}

The main aim of the paper was to study the effect of different vacuum heat treatments on the microstructural and fracture behaviour of $\mathrm{Fe}-[1.5 \mathrm{Cr}-0.2 \mathrm{Mo}]-0.6 \mathrm{C}$ PM steel.

\section{Experimental conditions}

The composition of the investigated system was $\mathrm{Fe}-$ [1.5 Cr-0.2Mo]-0.6C. Graphite and AW wax powder (as lubricant) were added to a commercial $\mathrm{Fe}-\mathrm{Cr}-\mathrm{Mo}$ powder (namely Astaloy CrL, Höganäs AB) and then homogeneised in a Turbula mixer for $20 \mathrm{~min}$. Specimens with a green density of approximately $7.0 \times 103 \mathrm{~kg} \mathrm{~m}^{-3}$ were obtained using a $2000 \mathrm{kN}$ hydraulic press, applying a pressure of $700 \mathrm{MPa}$. Two different specimen types were prepared: "dog-bone" tensile (ISO 2740) and unnotched impact energy $55 \times 10 \times 10 \times 10^{-3} \mathrm{~m}^{3}$ (ISO 5754). Specimens were debinded before sintering in a Nabertherm type furnace.

The heat treatment conditions consisted of the sintering process in a vacuum furnace at $1393 \mathrm{~K}$ for $1800 \mathrm{~s}$ with an integrated final tempering at $473 \mathrm{~K}$ for $3600 \mathrm{~s}$. The average cooling rates were calculated in the range of $1393 \mathrm{~K}$ to $673 \mathrm{~K}$ and were $0.1,0.235,3$, and $6 \mathrm{~K} / \mathrm{s}$, respectively.

In vacuum furnaces, the cooling rate is generally determined by the pressure of the gas $\left(\mathrm{N}_{2}\right)$ introduced into the chamber. Different gas pressures were used $0 \mathrm{~Pa}$, $50 \mathrm{kPa}, 200 \mathrm{kPa}$, and $600 \mathrm{kPa}$. The cooling rate was monitored and recorded by means of thermocouples inserted in the central axis and close to the surface of the 
specimen. The processes run fully automatically and the documentation of the process is provided by the curves of the programmer to give reproducible results.

Sintered specimens were tested on a ZWICK Z100 machine and in an impact testing apparatus ZWICK RKP 450. Microstructures observations and fracture surface analysis were carried out using a light optical and scanning electron microscopy. The apparent hardness (measured on the surfaces of tested specimen) was determined by means of Vickers hardness indenter (HV10). Densities were evaluated using the water displacement method.

\section{Results}

The microstructure of the studied materials is presented in Figs. 1 and 2.
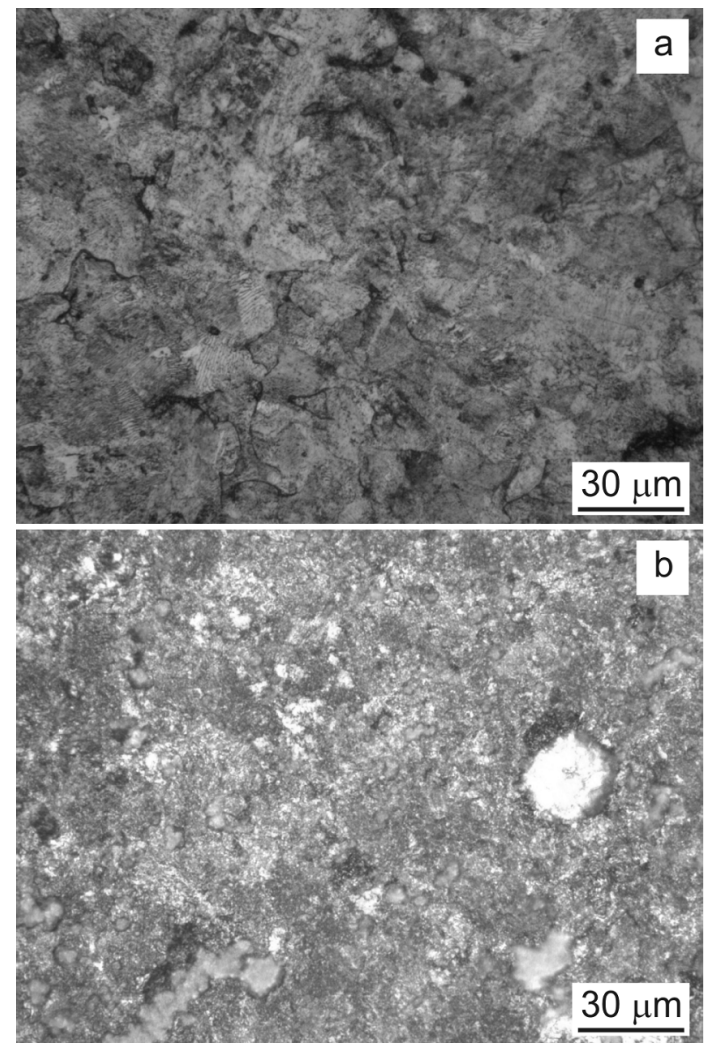

Fig. 1. Microstructure of material cooled at $0.1 \mathrm{~K} / \mathrm{s}$ (a) and $0.235 \mathrm{~K} / \mathrm{s}$ (b) rate, respectively.

At the lowest cooling rates, $0.1 \mathrm{~K} / \mathrm{s}$ (Fig. 1a), the microstructure consists predominantly of pearlite. In the system cooled at $0.235 \mathrm{~K} / \mathrm{s}$ (Fig. 1b), the microstructure is a mix of bainite and pearlite.

Increasing the cooling rate results in an increased amount of bainite/martensite. In the system cooled at $3 \mathrm{~K} / \mathrm{s}$ (Fig. 2a), the microstructure consists of a mix of martensite and bainite with a small amount of tempered martensite. In the system cooled at $6 \mathrm{~K} / \mathrm{s}$ (Fig. 2b), a dominantly martensitic microstructure with small amount of tempered martensite can be observed.
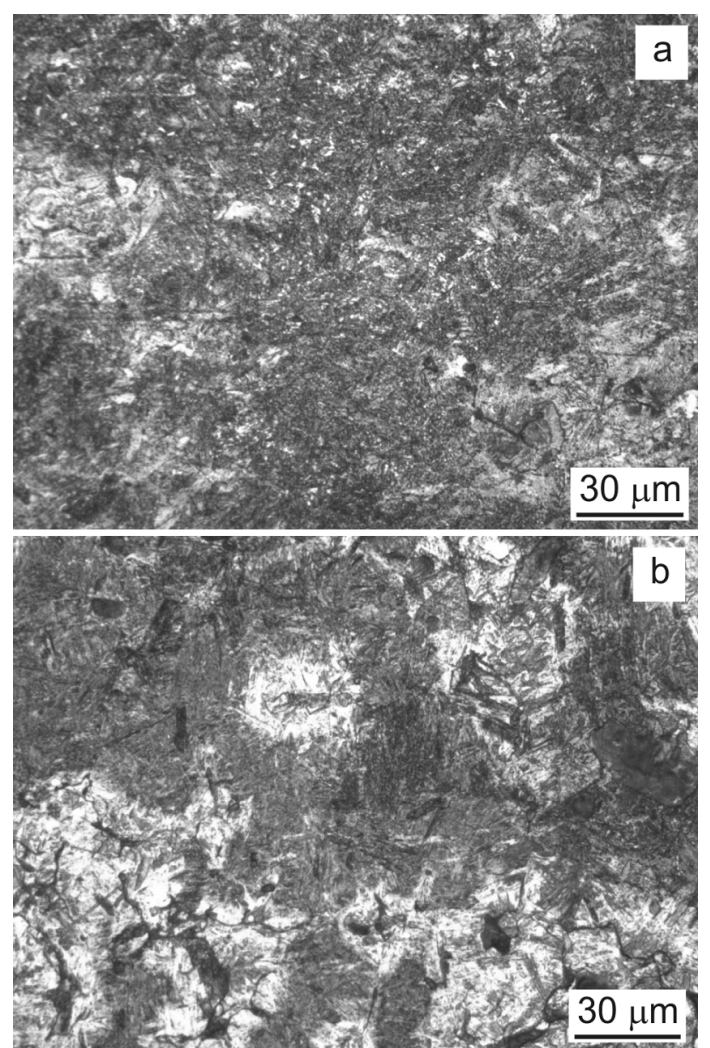

Fig. 2. Microstructure of material cooled at $3 \mathrm{~K} / \mathrm{s}$ (a) and $6 \mathrm{~K} / \mathrm{s}(\mathrm{b})$ rate, respectively.


Fig. 3. Fracture surface of material cooled at $0.1 \mathrm{~K} / \mathrm{s}$ and $0.235 \mathrm{~K} / \mathrm{s}$ rate, respectively. 


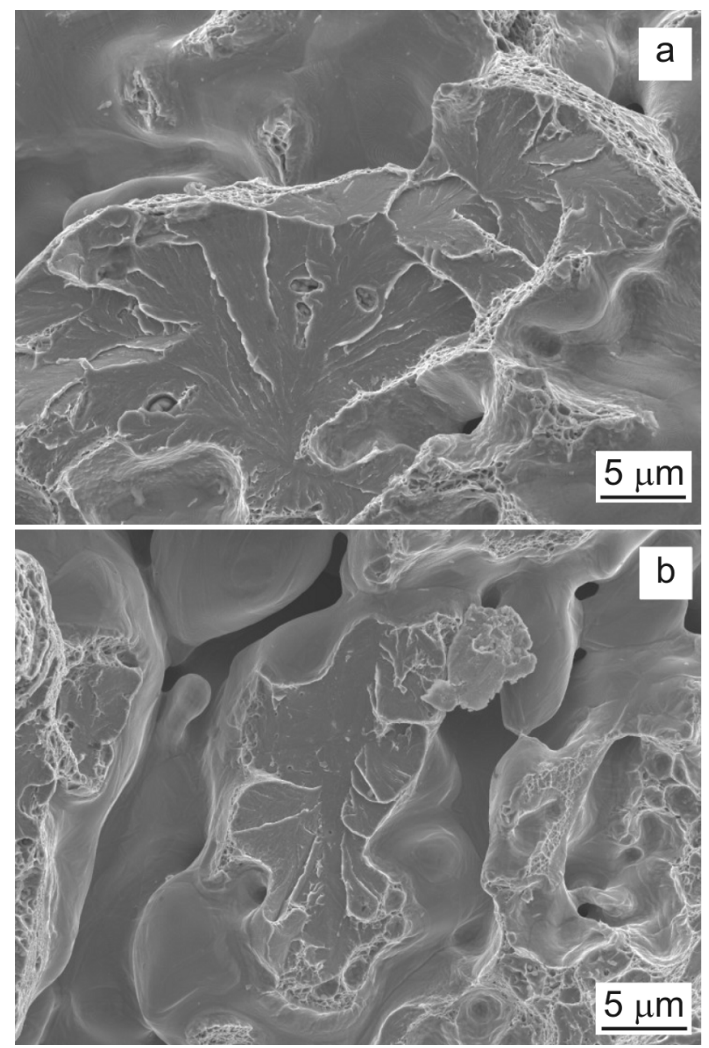

Fig. 4. Fracture surface of material cooled at $3 \mathrm{~K} / \mathrm{s}$ and $6 \mathrm{~K} / \mathrm{s}$ rate, respectively.
The fracture surfaces of investigated materials are presented in Figs. 3 and 4.

All surfaces show a basically brittle behaving material, but at higher magnifications, different fracture micromechanisms are detected. Figure 3a shows a ductile fracture surface with localised plastic flow, presumably formed principally of plastic deformation by slip. The pearlite microstructure features are dominant in the fracture surfaces. Figure 3b shows a ductile fracture surface.

Surfaces presented in Fig. 4a and Fig. 4b show a transgranular cleavage fracture mode. Figure 4a presents the transgranular cleavage with river patterns features. Figure $4 \mathrm{~b}$ presents two tilted transgranular cleavage planes, with river patterns features near the isolated pore.

Detailed information about microstructural constituents, the prevailing fracture surface mode and the mechanical properties are presented in Table.

The results of the mechanical properties evidence that with increasing values of transverse rupture strength (TRS), the impact energy values decrease. Several authors [16-18] suggest that the decrease of the impact energy after heat treatment is justified by the microstructural changes, mainly if a part of bainite is converted to brittle martensite.

\section{TABLE}

Microstructural constituents, prevailed fracture surface mode and mechanical properties.

\begin{tabular}{|c|c|c|c|c|c|c|c|c|}
\hline \multirow{2}{*}{$\begin{array}{c}\text { Cooling } \\
\text { rate } \\
{[\mathrm{K} / \mathrm{s}]}\end{array}$} & \multicolumn{4}{|c|}{$\begin{array}{l}\text { Microstructure } \\
\text { constituent }\end{array}$} & \multirow[t]{2}{*}{ Fracture surface } & \multicolumn{3}{|c|}{$\begin{array}{l}\text { Mechanical } \\
\text { properties }\end{array}$} \\
\hline & $\begin{array}{c}P \\
{[\%]}\end{array}$ & $\begin{array}{c}F \\
{[\%]}\end{array}$ & $\begin{array}{c}B \\
{[\%]}\end{array}$ & $\begin{array}{c}M \\
{[\%]}\end{array}$ & & $\begin{array}{c}\text { TRS } \\
{[\mathrm{MPa}]}\end{array}$ & $\begin{array}{l}\mathrm{IE} \\
{[\mathrm{J}]}\end{array}$ & HV10 \\
\hline 0.1 & 97 & 3 & - & - & $\begin{array}{l}\text { ductile, localised } \\
\text { plastic flow }\end{array}$ & 934 & 17.0 & 191.2 \\
\hline 0.235 & 77 & - & 23 & - & $\begin{array}{c}\text { ductile, localised } \\
\text { plastic flow occasionally }\end{array}$ & 1009 & 16.8 & 193 \\
\hline 3 & - & - & 32 & 68 & $\begin{array}{c}\text { cleavage, localised } \\
\text { plastic flow occasionally }\end{array}$ & 1114 & 13.9 & 220.4 \\
\hline 6 & - & - & 18 & 82 & $\begin{array}{l}\text { quasi-cleavage, cleavage, } \\
\text { shallow dimple }\end{array}$ & 1211 & 9.3 & 435.8 \\
\hline
\end{tabular}

\section{Discussion}

Table focuses on the influence of microstructure and prevailing fracture surfaces on the mechanical properties. Results in Table indicate that the microstructure and fracture investigations properly match with the results of strength and ductility. The strength of heat-treated PM steels depends on the base powder, the carbon content, the cooling rate, the density and sintering; the combination of those variables may lead to the attainment of a hardened steel preserving adequate ductility and fracture toughness. The admixed microstructures of bainite and martensite predominantly affect the strength of the material. The obtained strength levels, coupled to the microstructures and fracture surfaces, confirm that cool- 
ing rates of about 2 bar $(3 \mathrm{~K} / \mathrm{s})$ are sufficient to obtain a mixed bainite and martensite microstructure.

Samples with bainitic microstructure presented higher impact energies than those with martensitic microstructure. This is fully confirmed by the fracture surface mode at higher magnification revealing two main micromechanisms of fracture: brittle (transgranular cleavage fracture) and ductile (dimples and plastic deformation by slip). The brittleness is also caused by a complex effect of microstructure heterogeneity around huge contaminations (complex refractory oxides, where chromium oxide is dominant), mainly in places surrounding the original powder particles. Karlsson et al. reveal [19] that oxides can be formed during the atomisation of low alloyed chromium sintered steels. These oxides are much harder to be reduced in subsequent processing. Such a layer of oxides keeps covering the surfaces of the annealed powders and consequently oxides are found entrapped in the sinter necks, Fig. 5 and Fig. 6.

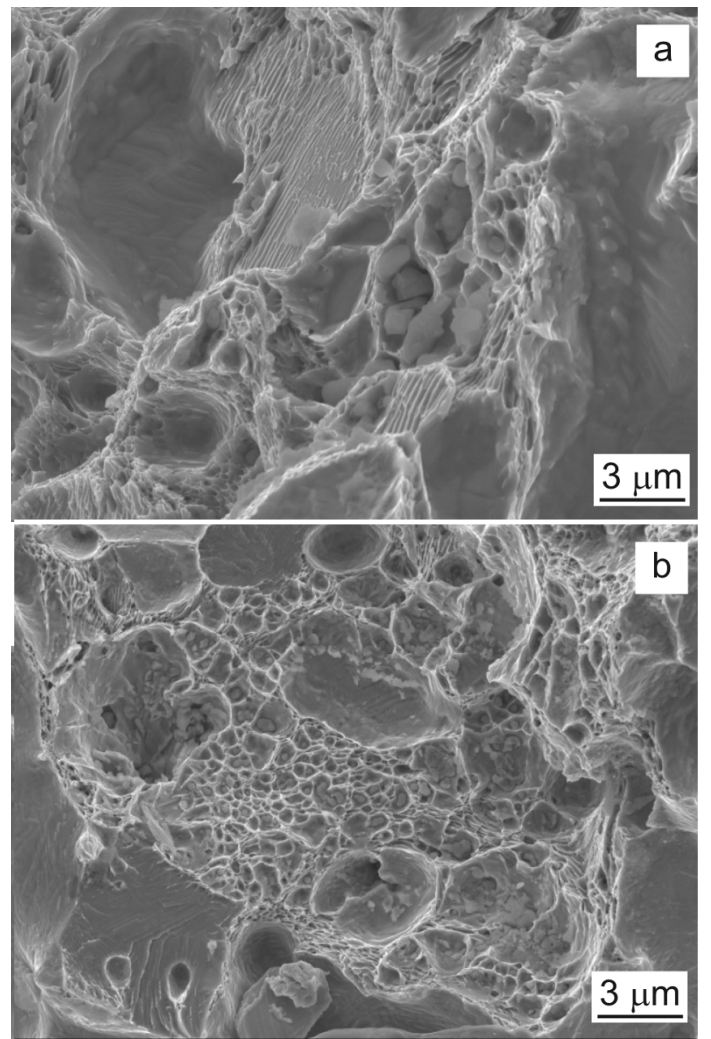

Fig. 5. Trapped oxides inside pores in the fracture surface of material cooled at $0.1 \mathrm{~K} / \mathrm{s}$ and $0.235 \mathrm{~K} / \mathrm{s}$ rate, respectively.

The pores cause the distribution of stress to be inhomogeneous across the cross-section and fractionate the fracture surfaces to the various fracture micromechanisms: quasi-cleavage/cleavage and ductile with shallow dimple.

Figure 5 and Fig. 6 reveal a microvoid coalescence fracture mechanism between adjacent powder particles. The formation of microvoids indicates that an interparticle
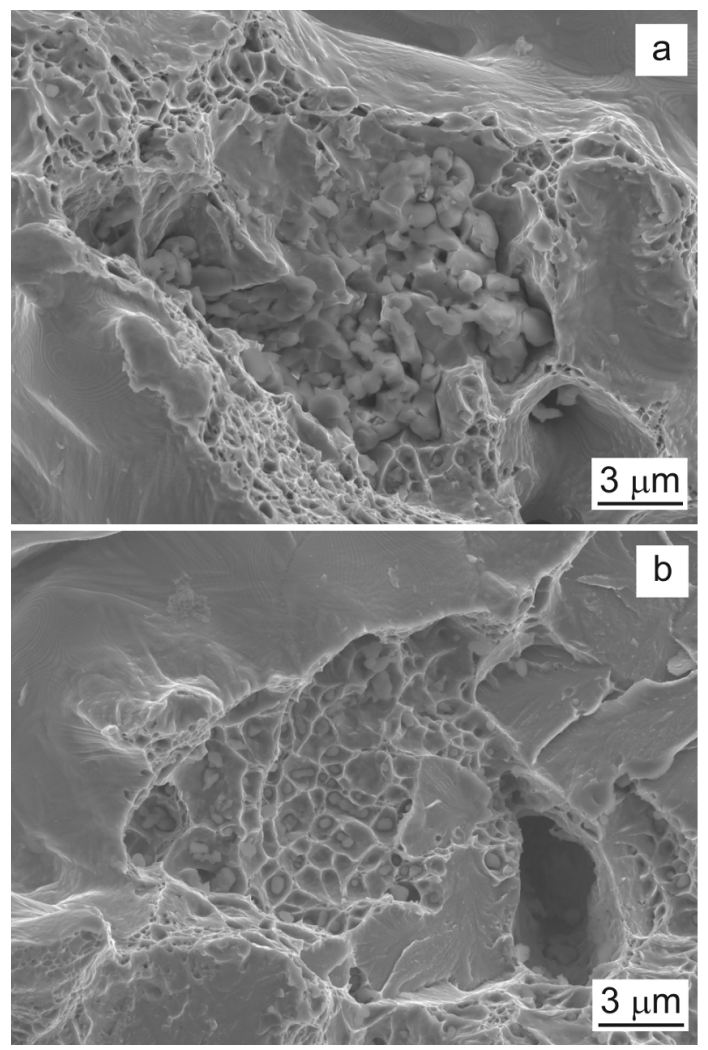

Fig. 6. Trapped oxides inside pores in the fracture surface of material cooled at $3 \mathrm{~K} / \mathrm{s}$ and $6 \mathrm{~K} / \mathrm{s}$ rate, respectively.

ductile fracture occurred at the powder particle contacts. Moreover, impurity segregation (oxides) and pores play a role in the transition route from the interparticle ductile fracture to brittle mechanisms, mainly in the region adjacent to the powder particles and/or the grain boundaries.

Another possible transition route for a quasi-cleavage mechanism that was noticed ran along the interface between two different phases, that is to say between the lower bainite (lath bainite) and transformed martensite (tempered martensite). This could be attributed to the different hardness at the two neighbour microstructure phases, which caused dislocation pile-ups at the interface and, according to [20], a concentration of stresses. According to $[21,22]$, these fracture behaviours are called quasi-cleavage, especially in the fracture of quenched and tempered steels. In any case, Krauss [21] underlined that the line between the terms "cleavage" and "quasi-cleavage" is somewhat arbitrary. Other authors stated [23-25] that quasi-cleavage is frequently decorated with fine lines called river markings running approximately parallel to the crack propagation direction. They originate in the grain interior rather than at the grain boundary and the river markings on opposing fracture surfaces match ridge-to-ridge as opposed to mating step-to-step as in cleavage [25]. 
However, the correlation of this surface with the underlying microstructure is not fully understood and, consequently, the formation mechanism has not been identified so far. Nevertheless, such single event models are not sufficient to describe the quasi-cleavage mode often observed in tempered martensitic steels.

Quasi-cleavage is characterized by single or small clusters of planar cleavage facets, separated from other co- planar facets or clusters of facets by ductile tear. Prior austenitic grains contain several misoriented lath packets which constitute the basic unit of crystallographic orientation. Quasi-cleavage involves frequent microcrack nucleation and propagation events, stopping at misoriented lath packet or prior austenite grain boundaries.

The lack of understanding of the quasi-cleavage micromechanism is due to the limited knowledge of microstructure/fracture development for the studied low alloyed PM microstructures at high cooling rate $(3$ and $6 \mathrm{~K} / \mathrm{s}$ ). The "traditional" PM pecularities (sintered necks, localized strain, grain boundaries, pores, original powder particles, second phases) play a very important role and these pecularities cause more differences in microfracture modes if compared to the wrought materials.

The fracture behavior of vacuum heat treated low alloyed steels cooled at higher rates (more than $2 \mathrm{~K} / \mathrm{s}$ ) is relatively unexplored. Previous articles dealt with the mechanical properties and microstructure development $[9,10,26,27]$, whereas the proposed paper explores the correlation between fracture modes, microstructure development and material properties. The obtained results show that the vacuum heat treatments of low alloyed sintered steel containing $\mathrm{Cr}$ and $\mathrm{Mo}$ is an effective instrument for microstructural hardening, to obtain high-strength sintered steels suitable for the production of highly loaded mechanical parts.

\section{Conclusion}

1. Vacuum heat treatment is supporting the bainitic-martensitic microstructure, the higher the faster cooling rate applied. This provides a marked increase in strength coupled to a decrease in ductility.

2. Different micromechanisms of fracture were identified in the evaluated systems: brittle (quasi-cleavage and cleavage) and ductile (dimples and plastic deformation by slip).

3. Results indicate the strong correlation between microstructure, fracture surfaces and the mechanical properties, in terms of strength and ductility.

\section{Acknowledgments}

J. Bidulská thanks Slovak national projects VEGA $1 / 0385 / 11$.

\section{References}

[1] E. Hryha, L. Čajková, E. Dudrová, Powder Metall. Prog. 7, 181 (2007).

[2] E. Hryha, E. Dudrova, L. Nyborg, Metall. Mater. Trans. A 41, 2880 (2010).

[3] M. Selecká, A. Šalak, Int. J. Powder Metall. 46, 29 (2010).

[4] J. Bidulská, T. Kvačkaj, R. Bidulský, M. Actis Grande, High Temp. Mater. Process. 27, 203 (2008).

[5] J. Bidulská, T. Kvačkaj, R. Bidulský, M. Actis Grande, T. Donič, M. Martikán, Acta Metall. Slovaca 16, 4 (2010).

[6] R. Bidulský, J. Bidulská, M. Actis Grande, High Temp. Mater. Process. 28, 337 (2009).

[7] M. Kvačkaj, T. Kvačkaj, A. Kováčová, R. Kočiško, J. Bacsó, Acta Metall. Slovaca 16, 84 (2010).

[8] S.C. Mitchell, A. Cias, Powder Metall. Prog. 4, 132 (2004).

[9] M. Zendron, L. Girardini, A. Molinari, Powder Metall. 51, 237 (2008).

[10] S. Hatami, A. Malakizadi, L. Nyborg, D. Wallin, J. Mater. Process. Technol. 210, 1180 (2010).

[11] E. Hryha, C. Gierl, L. Nyborg, H. Danninger, E. Dudrova, Appl. Surf. Sci. 256, 3946 (2010).

[12] M. Hrubovcakova, E. Dudrova, Acta Metall. Slovaca 15, 248 (2009).

[13] J. Bidulská, R. Bidulský, M. Actis Grande, Acta Metall. Slovaca 16, 146 (2010).

[14] R. Bidulský, M. Actis Grande, High Temp. Mater. Process. 27, 249 (2008).

[15] R. Bidulský, M. Actis Grande, Z. Brytan, M. Rosso, Mater. Sci. Forum 672, 293 (2011).

[16] N. Candela, F. Velasco, J.M. Torralba, Mater. Sci. Eng. A 259, 98 (1999).

[17] M. Campos, L. Blanco, J.M. Torralba, Powder Metall. Prog. 7, 12 (2007).

[18] R. Bidulský, M. Actis Grande, J. Bidulská, T. Kvačkaj, Mater. Tekhnol. 27, 249 (2008).

[19] H. Karlsson, L. Nyborg, S. Berg, Powder Metall. 48, 51 (2005).

[20] M.W. Wu, K.S. Hwang, H.S. Huang, Metall. Mater. Trans. A 38, 1598 (2007).

[21] G. Krauss, Metall. Mater. Trans. A 32, 861 (2001).

[22] V. Kerlins, A. Phillips, in: Fractography, 9th ed., Metals Handbook, ASM International, Ohio 1987, p. 12.

[23] S.P. Lynch, Acta Metall. 32, 79 (1984).

[24] A.W. Thompson, Fatig. Fract. Eng. Mater. Struct. 19, 1307 (1996).

[25] M.L. Martin, J.A. Fenske, G.S. Liu, P. Sofronis, I.M. Robertson, Acta Mater. 59, 1601 (2011).

[26] U. Engström, D. Milligan, A. Klekovkin, Adv. Powder Metall. Particul. Mater. 7, 21 (2006).

[27] T. Marcu Puscas, M. Signorini, A. Molinari, G. Straffelini, Mater. Charact. 50, 1 (2003). 